\title{
State minimum wages and health insurance coverage in the United States: 2008-2018
}

\section{Masanori Kuroki ${ }^{1}$ (iD}

Received: 7 May 2021 / Accepted: 30 August 2021 / Published online: 8 September 2021

(C) The Author(s), under exclusive licence to Springer Science+Business Media, LLC, part of Springer Nature 2021

\begin{abstract}
This study examines the effect of minimum wage hikes on the shares of uninsured people during the period 2008-2018. Despite some concern that higher minimum wages would lead to higher uninsured rates by (1) reducing employment, (2) inducing employers to stop offering health insurance to their employees, and (3) making minimum wage workers ineligible for Medicaid by increasing their earnings, the findings indicate that the uninsured rate tends to decrease with higher minimum wages, suggesting that minimum wage hikes might encourage minimum-wage workers to obtain health insurance. The effects appear to come from minimum wage hikes that occurred after the Affordable Care Act (ACA) took effect in 2014, suggesting that higher minimum wages combined with federal subsidies for the ACA marketplace and the individual mandate might have contributed to a reduction in the uninsured rate. However, Medicaid expansions seem to mitigate the effect of the minimum wage on the uninsured rate among low-income households.
\end{abstract}

Keywords Minimum wage $\cdot$ Health insurance $\cdot$ Health care

JEL Classification G52 $\cdot$ I13 $\cdot$ J31

\section{Introduction}

While the federal minimum wage in the United States has not changed since 2009 from $\$ 7.25$ an hour, ${ }^{1}$ many states have their own minimum wage that is higher than the federal amount. Policymakers in states that raise the minimum wage are mainly concerned with the adverse labor market effects, but more and more studies examine the health effects of minimum wage hikes (see Leigh et al., 2019 for a review). One unintended consequence of a minimum wage increase might be its effect on health insurance coverage. There are three channels in which a hike in the minimum wage might increase the share of uninsured people. First, minimum wage workers who receive Medicaid may start earning income too

\footnotetext{
1 As of August 2021, there is no increase in the federal minimum wage in the foreseeable future, though the coronavirus pandemic reinvigorated the discussion and debate about the minimum wage.

Masanori Kuroki

mkuroki@atu.edu

1 College of Business, Arkansas Tech University, Russellville, USA
} 
high to qualify for Medicaid and lose eligibility. Second, higher minimum wages may lead to losses in employer coverage by reducing employment, and unemployed people might choose to remain uninsured. Finally, higher minimum wages may lead to lower fringe benefits, including health insurance, as employers may respond to higher labor costs by adjusting non-wage job attributes such as fringe benefits. However, evidence is mixed. Simon and Kaestner (2004) found little evidence that minimum wage increases reduced employersponsored health insurance during the 1980s and 1990s, but Clemens et al. (2018) found that state-level minimum wage hikes decreased the likelihood that people report having employer-sponsored health insurance, mainly among low-paying occupations, using the 2011-2016 American Community Survey.

Nevertheless, a higher minimum wage could work in the opposite direction and increase the share of insured people. A higher minimum wage could help previously uninsured workers in low-wage jobs afford employer-sponsored insurance. Currently, most Americans obtain health insurance through employer-based coverage, but many workers do not accept the option of coverage from an employer due to the high costs (Bindman, 2015). Alternatively, a higher minimum wage could encourage previously uninsured workers to buy insurance through the Affordable Care Act (ACA) marketplace, where federal subsidies are available to support eligible individuals with incomes up to $400 \%$ of the federal poverty line. Thus, whether higher minimum wages increase or decrease overall health insurance coverage is an empirical question. For these reasons, it is important to investigate whether higher minimum wages affect the overall uninsured rate, not just employersponsored coverage. Given that most minimum wage hikes take place at the state level, if minimum wage hikes lead to lower overall health insurance coverage at the state level, it will be an important reminder about the potential costs of higher minimum wages for policymakers to consider. The contribution of this study is to provide empirical evidence on whether minimum wage increases are associated with overall health insurance coverage at the state level.

To examine the effect of minimum wages on the shares of uninsured people, this study first uses event study models to test for parallel pre-trends and capture the time path of effects around the time of minimum wage increases. Then, difference-in-differences models that leverage panel variation in state minimum wages over time are estimated. Finally, the difference-in-differences approach is augmented with a triple-difference analysis, in which the highest-income group is used as a "within-state control" group to account for a possibility that states were trending differentially over time but in a similar manner across different income groups. The findings indicate that higher minimum wages did not lead to higher uninsured rates during the period 2008-2018. On the contrary, there is evidence that the uninsured rate decreases with higher minimum wages, indicating that minimum wage hikes might encourage minimum-wage workers to obtain health insurance. The effects appear to come from minimum wage hikes that occurred after the Affordable Care Act (ACA) took effect in 2014, suggesting that higher minimum wages combined with federal subsidies for the ACA marketplace and the individual mandate might have contributed to a reduction in the uninsured rate after 2014. However, Medicaid expansions seem to mitigate the effect of the minimum wage on the uninsured rate among low-income households. 
Table 1 Summary statistics

\begin{tabular}{lllll}
\hline Statistic & Mean & SD & Min & Max \\
\hline \% uninsured (0-138\% FPL) & 30.89 & 11.39 & 6.73 & 57.84 \\
\% uninsured (138-200\% FPL) & 27.04 & 9.06 & 8.09 & 49.39 \\
\% uninsured (200-250\% FPL) & 21.27 & 6.94 & 7.19 & 41.58 \\
$\%$ uninsured (250-400\% FPL) & 13.75 & 4.72 & 4.69 & 28.97 \\
$\%$ uninsured (>400\% FPL) & 5.42 & 2.03 & 1.60 & 12.41 \\
Real minimum wage & 8.32 & 0.89 & 6.86 & 13.25 \\
Medicaid expansion & 0.31 & 0.46 & 0 & 1 \\
Unemployment & 6.2 & 2.2 & 2.4 & 13.7 \\
Median income & 54,516 & 9839 & 36,764 & 83,076 \\
Poverty & 13.7 & 3.1 & 7 & 23 \\
\hline
\end{tabular}

\section{Data and methods}

The data on health insurance coverage are obtained from the 2008-2018 Small Area Health Insurance Estimates (SAHIE) program of the U.S. Census Bureau (2021). As the District of Columbia is included in addition to fifty states, the resulting sample size is 561 $(51 \times 11$ years $)$. The SAHIE's definition of insured includes both private insurance and any kind of public insurance (Medicaid, VA health care, TRICARE etc.), and the estimates exclude those who are above age 65. The SAHIE data are available for six income categories: all incomes, $0-138 \%, 0-200 \%, 0-250 \%, 0-400 \%$, and $138-400 \%$ of the federal poverty level (FPL). Using these income categories, the following five income categories are created: (1) $0-138 \%$, (2) $138-200 \%$, (3) $200-250 \%$, (4) $250-400 \%$, and (5) $>400 \%$ of the FPL. These income categories are analyzed separately. Table 1 shows the uninsured rate for each income group. The population shares of uninsured people, not surprisingly, decline with income.

Reasonable observers may rightly point out that households that earn more than, say, twice the FPL might not contain minimum wage workers. While the federal minimum wage of $\$ 7.25$ only results in approximately $\$ 15,000$ a year for a full-time worker, there are two justifications for including these groups. First, many minimum wage workers are not breadwinners of low-income families but people with spouses who are paid more than the minimum wage. Also, many minimum wage workers have a household income greater than $200 \%$, or even $250 \%$, of the FPL. To illustrate, consider a two-adult household, for whom the FPL was $\$ 16,460$ in 2018 , when fourteen states had a minimum wage above $\$ 10$. Two workers making $\$ 10$ an hour working $2000 \mathrm{~h}$ a year would have a household income of $\$ 40,000$, which is almost $250 \%$ of the FPL, $\$ 41,000$. $^{2}$

Second, there is evidence that higher minimum wages lead to higher wages among lowskilled workers who earn wages above the minimum wage. Workers form expectations of "fair" wages by comparing their wages to those of other workers, and higher minimum wages change their reservation wages (Falk et al., 2006) as they feel they should be paid more if the lowest-paid employees are paid more. This in turn encourages employers to raise the wages of those employees who use the minimum wage as a benchmark, to maintain morale and productivity. Autor et al. (2016) documented this spillover effect of higher

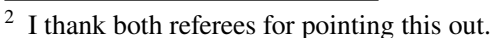


minimum wages on the wages of workers earning above the minimum wage. Clemens et al. (2018) also found that the probability of employer-sponsored coverage decreased with minimum wage hikes among workers in modest-paying occupations, suggesting a non-trivial role for spillovers.

The state-level minimum wage data are obtained from the U.S. Department of Labor's (2020) Changes in Basic Minimum Wages in Non-Farm Employment Under State Law. Wage rates are for January 1 of each year. During the sample period, the federal minimum wage increased to $\$ 6.55$ in July 2008 from $\$ 5.85$ and to $\$ 7.25$ in July 2009 , and there were 152 state-level minimum wage hikes. Table 5 in the appendix shows these changes. Since there are states with no minimum wage law (Alabama, Louisiana, Mississippi, South Carolina, and Tennessee) and states with minimum wages below the federal level (Georgia and Wyoming), the effective minimum wage is defined as the higher of the state and federal minimum wage in each state. The nominal minimum wage is converted to 2018 dollars using the Consumer Price Index obtained from the Federal Reserve Bank of St. Louis (2021). In this study, city and county minimum wages are not considered, as the data on health insurance coverage are at the state level.

To control for time-varying local economic conditions, median household income, poverty rates, and unemployment rates are included in the analysis below. State-level annual median household income and poverty rates are obtained from the U.S. Census Bureau (2020a) Small Area Income and Poverty Estimates (SAIPE) Program. State-level annual unemployment rates are obtained from the Bureau of Labor Statistics (2020) Statewide Data, Annual Average Series. Finally, an indicator variable for post Affordable Care Act Medicaid expansion is included, as Medicaid expansions were more common in states that increased minimum wages (Clemens et al., 2018). Information on the ACA Medicaid expansions is obtained from the Kaiser Family Foundation (2021). However, since some states expanded Medicaid after January, the variable is adjusted to take into account the pre-expansion period. For example, Michigan expanded Medicaid in April 2014, and thus the variable for Michigan equals $9 / 12=0.75$ for 2014 and one from 2015 to 2018. Summary statistics for these state-level covariates are reported in Table 1.

While these state-level characteristics will be controlled for in the analysis below, it may be useful to be aware of the differences between states that frequently raise the minimum wage and states that do not. ${ }^{3}$ Table 6 in the appendix shows summary statistics separately for "minimum wage states," where the minimum wage was higher than the federal level during any given year, and "non-minimum wage states," where the minimum wage was equal to or lower than the federal level. There are 35 minimum wage states and 16 nonminimum wage states. Minimum wage states not only have lower uninsured rates but also lower poverty rates and higher household incomes. Importantly, they are likely to be Medicaid expansion states. As of 2018, out of 32 states that have expanded Medicaid, 28 states were minimum wage states. This suggests that states that raise the minimum wage may have different economic, social, and political structures from states that do not. ${ }^{4}$ The expansion of Medicaid is of particular relevance to this study, as it directly affects the uninsured

\footnotetext{
3 I thank a referee for suggesting this.

4 Allegretto et al. (2017) state, "[h]igh minimum wage states are concentrated on the Pacific Coast, the Northeast, and parts of the Midwest; tend to be Democratic-leaning; and have experienced less de-unionization. These disparities raise the possibility that trends in other policies and economic fundamentals may also differ between these groups of states." (p. 560).
} 
rate among lower income households. Thus, heterogeneous treatment effects with respect to Medicaid expansions will be explored below.

As states are extremely heterogeneous in size, the estimation technique used is weighted least squares with weights proportional to state population obtained from the U.S. Census Bureau (2020b). The dependent variable is the share of uninsured people for each income group, and the independent variable of interest is the minimum wage. The following difference-in-differences regression is estimated:

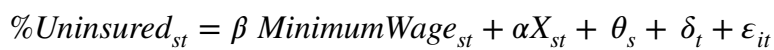

where $s$ and $t$ denote, respectively, state and year. The coefficient of interest $\beta$ is a difference-in-differences estimator of the effect of changes in the minimum wage on the uninsured rate. $X_{s t}$ is state-level covariates mentioned above.

In the difference-in-differences models, the treatment group is composed of states that increased their minimum wages, while the control group is composed of states that did not. One concern is that insurance coverage in states that did and did not increase minimum wages might have followed different trends, violating the parallel trends assumption, i.e. conditional on the control variables included in the model, the uninsured rate would have followed similar trends across states if not for differential changes in their minimum wage policy, and changes in state minimum wages should be uncorrelated with unobserved drivers of health insurance coverage. The assumption would be violated if there was some time-varying confounder that changed differentially across the states. To increase the likelihood that the parallel trends assumption holds, this study augments the difference-in-difference model with two additional models: event study models and tripledifference models.

As a generalized extension of difference-in-differences models, event study models allow for dynamic lags and leads to the event of interest to be estimated. Specifically, the purpose of the event study model is twofold. First, if the minimum wage has any effect on the uninsured rate, event study models can show a rise or drop in the uninsured rate following change in the minimum wage. Second, the event study models can be used to check for pre-trends, i.e. the possibility that the uninsured rate tends to trend upward or downward in the time leading up to events.

The standard event study model has one event per state with a set of mutually exclusive dummy variables, each equal to one when an event is a certain number of periods away. However, in the case of minimum wage hikes, there are two methodological issues: (1) minimum wage policies vary in magnitude, and (2) multiple minimum wage increases often occur in the same state in quick succession. Unfortunately, there is no clear consensus on how to conduct an event study when events occur multiple times per unit and their treatment intensity differs both across states and across events. ${ }^{5}$

This study adopts the strategy shown in Schmidheiny and Siegloch (2019). First, the intensity of minimum wage hikes is used instead of dummy variables. For example, if a minimum wage hike was $\$ 0.50$, the event study variable for "two periods before an event" would be equal to 0.5 two periods before the event, and zero other times. Also, as there are multiple events per state, if a given state in a given year was, for example, both 2 years

\footnotetext{
5 Typically, those kinds of models are estimated in a distributed-lag model in first differences (Schmidheiny \& Siegloch, 2019).
} 
after a minimum wage hike and 1 year before another minimum wage hike, both relevant event variables are the exact size of a change in the minimum wage. Second, the endpoints are "binned" to implicitly assume that the effect builds up to the endpoint and stays constant thereafter. ${ }^{6}$

While the health insurance data cover 2008-2018, the minimum wage data are available up to 2021. Minimum wage hikes occurring between 2004 and 2021 (i.e. 3 years before and after each change in the minimum wage so that the minimum wage in 2021 can be used for the uninsured rate in 2018) are utilized. The number of lags and leads is four, and both endpoints are binned. ${ }^{7}$ As an illustration, Table 7 in the appendix shows how event study variables for endpoints are binned using two states: Oregon, which had many minimum wage changes, and Texas, which only had the federal minimum wage changes. The basic idea of binned event study variables at the endpoints is that the maximum lag (lead) takes into account all observable past (future) events going beyond the effect window. The event study regression takes the following form:

$$
\text { \% } \text { Uninsured }_{s t}=\sum_{k=-4, k \neq-1}^{4} \beta^{k} d_{s t}^{k}+\alpha X_{s t}+\theta_{s}+\delta_{t}+\varepsilon_{s t}
$$

where

$$
\begin{aligned}
d_{s t}^{k} & =\sum_{k=-\infty}^{-4} \Delta \text { MinimumWage }_{s, t-k} \quad \text { if } k=-4 \\
d_{s t}^{k} & =\Delta \text { MinimumWage }_{s, t-k} \quad \text { if }-4<k<4 \\
d_{s t}^{k} & =\sum_{k=4}^{\infty} \Delta \text { MinimumWage }_{s, t-k} \quad \text { if } k=4
\end{aligned}
$$

where $\Delta$ MinimumWage $e_{s t}=$ MinimumWage $_{s t}-$ MinimumWage $_{s, t-1}$. Treatment variables $d_{s t}^{k}$ are binned at the endpoints $[-4,4] . k=-1$ is omitted as the reference period to normalize $\beta^{-1}$ to zero. Treatment effects $\beta^{k}$ are therefore expressed relative to 1 year prior to the event. If parallel pre-trends hold, the estimated coefficient should be statistically indistinguishable from zero for periods between -4 and -2 . If there is a short-term effect of minimum wage hikes, the estimated coefficients should shift discontinuously at the time of the hikes $(k=0)$. Positive coefficients for periods $1-4$ would suggest the dynamic effect of minimum wage hikes.

Finally, to further account for factors that potentially varied across states and over time, a triple-difference design is employed by including an additional comparison group. Specifically, income group " $>400 \%$ FPL" is used as a within-state-time comparison group that was not exposed to treatment but was exposed to potential time-varying confounders that were free from any treatment effect. Because the minimum wage policy primarily affects lower income households, one should expect to see no (relative) increase in the uninsured rate among the highest income group. If there was a distinct shock in high-minimum wage states over this period, the assumption is that the effects of these shocks should show up in

\footnotetext{
${ }^{6}$ Event study models without binned endpoints implicitly assume that treatment effects drop to zero outside of the effect window.

7 The binning method is described in detail in Schmidheiny and Siegloch (2019).
} 
health coverage among all households in these states. Thus, the triple-difference approach controls for the possibility of contemporaneous shocks in these states.

In the triple-difference model, all income groups are pooled in one regression, and income group dummies are interacted with the minimum wage. A triple-difference regression specification is as follows:

$$
\begin{aligned}
{\text { \% } \text { Uninsured }_{i s t}=} & \left(\beta_{1} \text { MinimumWage }_{s t}+\alpha_{1} X_{s t}\right) \times{\text { Income } 0-138 \% F P L_{i}} \\
& +\left(\beta_{2} \text { MinimumWage }_{s t}+\alpha_{2} X_{s t}\right) \times{\text { Income } 138-200 \% F P L_{i}} \\
& +\left(\beta_{3} \text { MinimumWage }_{s t}+\alpha_{3} X_{s t}\right) \times{\text { Income } 200-250 \% F P L_{i}} \\
& +\left(\beta_{4} \text { MinimumWage }_{s t}+\alpha_{4} X_{s t}\right) \times \text { Income } 250-400 \% F P L_{i} \\
& +\lambda_{i s}+\theta_{s t}+\delta_{i t}+\varepsilon_{i s t}
\end{aligned}
$$

where $i$ denotes income group. The triple-difference estimator is the differential impact of minimum wage increases on the uninsured rate for each income group, relative to the omitted income group ( $>400 \%$ FPL). State-level covariates are also interacted with income group dummies to allow the uninsured rate to be differentially sensitive to economic conditions and Medicaid expansions. The regressions also include all standard two-way fixed effects. State-by-year fixed effects $\theta_{s t}$ remove any confounding effect that uniformly affects households within a state in a particular period. State-by-group fixed effects $\lambda_{i s}$ account for the possibility that certain income groups in some states are more likely to have health insurance than in other states. Group-by-year fixed effects $\delta_{i t}$ allow health insurance coverage to trend differently across income groups on a national basis. The triple-differences model may generate more convincing results than the difference-in-differences model by exploiting three sources of variation instead of two.

\section{Results}

\section{Event studies}

Figure 1 shows the results from the event study model. Recall that the parameters are normalized so that the coefficient equals zero one year before the policy went into effect-that is, at -1 on the horizontal axis. As is standard in the minimum wage literature, standard errors are clustered at the state level. If the parallel trends assumption holds, then we would expect that the estimated coefficients between -4 and -2 on the horizontal axis would be close to zero, and indeed this is the case. Point estimates are not significantly different from zero for all income groups for the years leading up to a minimum wage increase $(<-1)$. This supports parallel pre-trends, i.e. states that increased their minimum wages did not experience differential trends in uninsured rates in the years leading up to the implementation of the higher minimum wage.

The points between 0 and 4 on the horizontal axis indicate a change in the uninsured rate after the minimum wage increased, relative to that in the comparison states. At time 0 , the estimated event time coefficients exhibit a discontinuous downward shift for all income groups except for the highest income group, though none of the decline is statistically distinguishable from zero. After time 1, all income groups except for the highest income group experience a statistically significant drop in the uninsured rate, indicating a dynamic effect of the minimum wage. Overall, the event study models show a discontinuous, albeit 

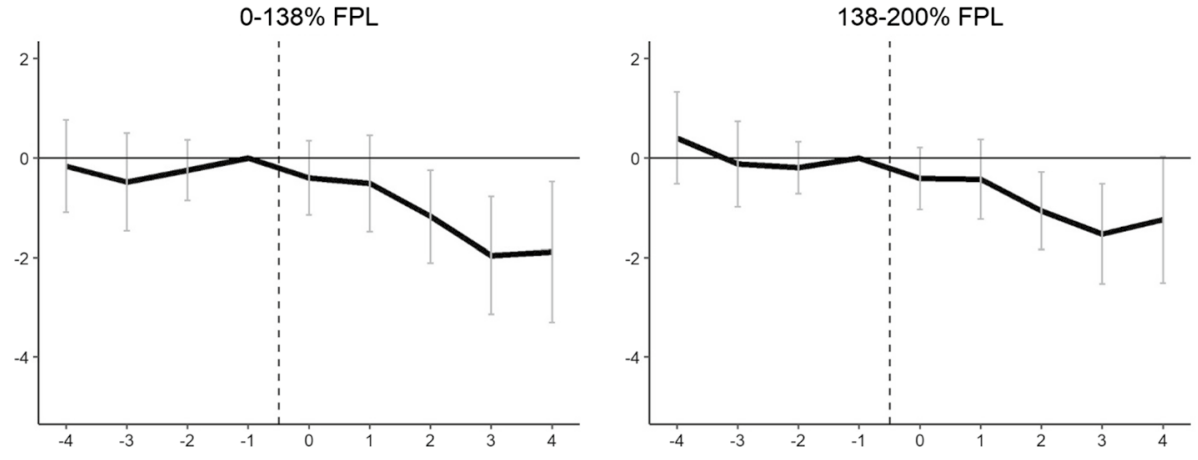

$200-250 \%$ FPL
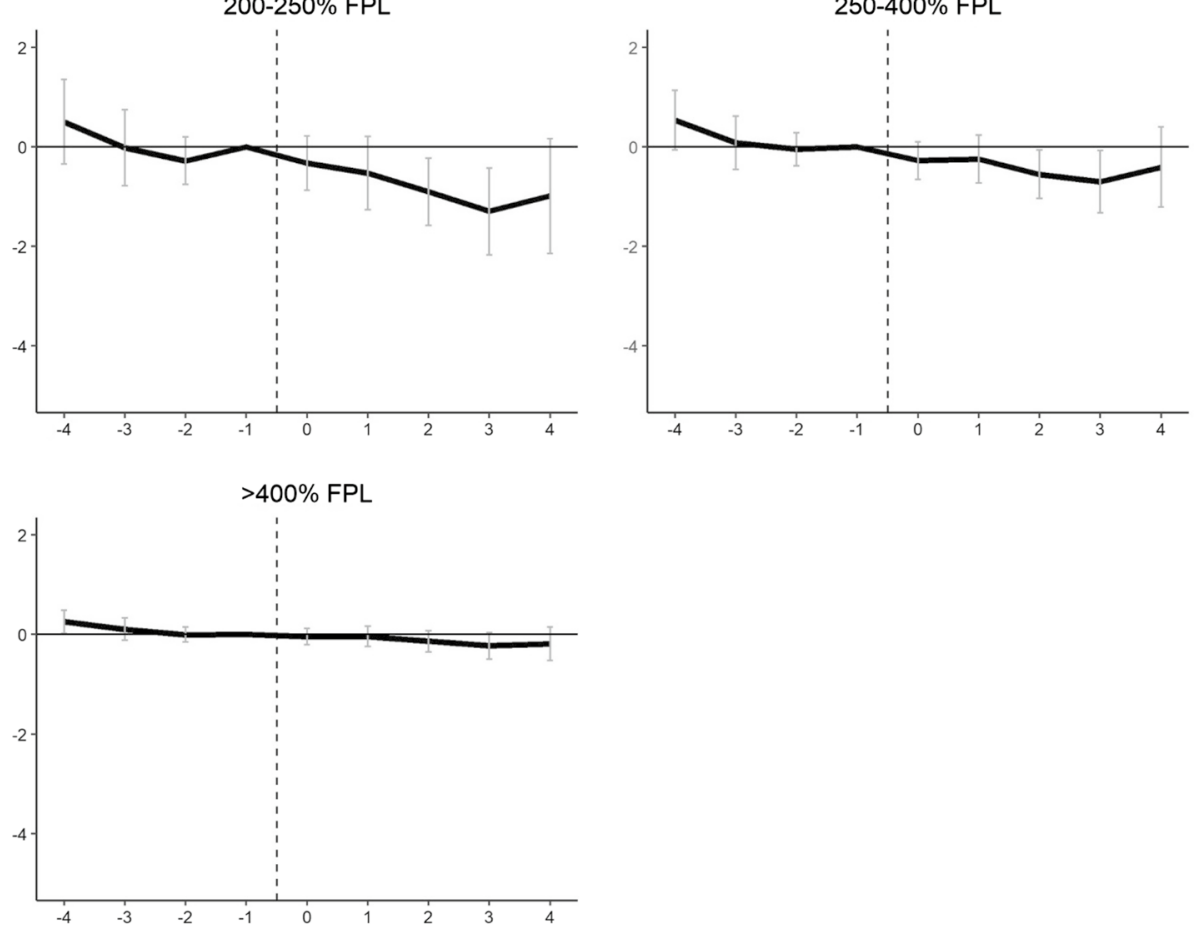

Fig. 1 Event study models. Note: The figure shows coefficient estimates from the event study. Standard errors are clustered at the state level. The regressions include state and year fixed effects as well as statelevel controls shown in Table 1. The parameters are normalized so that the coefficient equals zero at -1 on the horizontal axis

statistically insignificant, drop in uninsured rates at the time of minimum wage increases, as well as a downward trend in the uninsured rate following minimum wage hikes. Importantly, the event study models exhibit parallel pre-trends, which provide support for the difference-in-differences design. 
Table 2 Difference-in-differences regression results

Dependent variable: Share of uninsured people

0-138\% FPL 138-200\% FPL 200-250\% FPL 250-400\% FPL > 400\% FPL

(1)

\begin{tabular}{llllll}
\hline Minimum wage & -0.57 & -1.14 & $-1.21^{*}$ & $-1.00^{* *}$ & $-0.34^{*}$ \\
& $(0.65)$ & $(0.59)$ & $(0.50)$ & $(0.37)$ & $(0.14)$ \\
Medicaid expansion & $-4.79 * *$ & $-3.15^{* *}$ & $-2.27^{* *}$ & $-1.48^{* *}$ & $-0.60^{* *}$ \\
& $(0.73)$ & $(0.57)$ & $(0.47)$ & $(0.36)$ & $(0.14)$ \\
$\ln$ (Median income) & 9.61 & 13.12 & 11.91 & 10.88 & 4.54 \\
& $(18.64)$ & $(16.98)$ & $(14.50)$ & $(10.00)$ & $(3.94)$ \\
Poverty rate & 0.62 & 0.40 & 0.22 & 0.14 & 0.09 \\
Unemployment rate & $1.29 * *$ & $(0.38)$ & $(0.34)$ & $(0.25)$ & $(0.09)$ \\
& $(0.43)$ & $(0.46)$ & $0.96 *$ & $0.68 *$ & 0.22 \\
Observations & 561 & 561 & $(0.43)$ & $(0.33)$ & $(0.12)$ \\
\hline
\end{tabular}

${ }^{*} p<0.05, * * p<0.01$. Standard errors clustered at the state level are in parentheses. Regressions include state and year fixed effects

\section{Difference-in-differences}

Columns (1) and (2) in Table 2 show that the minimum wage has little effect on the uninsured rate among households that earned less than 200\% FPL, even though these two groups are most likely to be directly impacted by minimum wage policy. However, perhaps this is not too surprising as a substantial fraction of low-income households obtain insurance through Medicaid. The coefficients for higher income groups (200-250\% FPL, 250-400\% FPL, and > 400\% FPL) are statistically significant and negative. The magnitude suggests that a $\$ 1$ increase in the minimum wage is expected to decrease the uninsured rate by 1.0-1.2 percentage points for those making 200-400\% FPL and 0.3 percentage points for those making above $400 \%$ FPL. As for state-level covariates, Medicaid expansions are negatively and highly statistically significantly associated with uninsured rates for all income levels, while unemployment rates are positively associated. These estimates are larger in magnitude for lower income households.

The results above assume that the effect of the minimum wage is constant over time, but there is a strong reason to believe that the effect is different before and after the Affordable Care Act took effect in 2014. ${ }^{8}$ There are three major provisions at the federal level that are relevant for this study. First, the individual mandate took effect in January 2014 and required most people to obtain health insurance or pay a tax penalty. ${ }^{9}$ Second, people whose household incomes were between 100 and $400 \%$ of the FPL became eligible for federal subsidies for premiums for policies purchased on an ACA health exchange. ${ }^{10}$

\footnotetext{
${ }^{8}$ I thank a referee for pointing this out.

9 Legislation enacted in December 2017 effectively repealed that requirement, starting in 2019.

10 Often called the Health Insurance Marketplace, it is a regulated marketplace administered by either federal or state governments and provides health plan shopping and enrollment services to people and small businesses.
} 
Third, "the employer mandate" required employers to cover their workers, or pay penalties, with exceptions for small employers (fewer than 50 workers). Large employers, defined as those with 100 or more full-time workers, must offer health insurance or coverage beginning January 2015, while the employer mandate started in January 2016 for medium-sized employers with 50 employees to 99 employees (Cauchi, 2016).

Nevertheless, how the minimum wage increases affect the uninsured rate through these provisions is ambiguous. On one hand, the individual mandate and federal subsidies are likely to encourage minimum-wage workers to obtain health insurance, as they experience an increase in income after a minimum wage hike. On the other hand, the employer mandate might encourage employers to reduce hours or hire more part-time minimum-wage workers to avoid offering health insurance or paying penalties, to offset the higher labor costs caused by minimum wage hikes. This might increase the uninsured rate.

Another important provision of the ACA is the expansion of Medicaid, but it was not at the federal level, as the US Supreme Court decision made it optional for states to expand Medicaid coverage, for which childless adults had been for the most part ineligible in nearly all states. Several states enacted Medicaid expansions prior to 2014, and many states expanded Medicaid during the sample period 2014-2018. The expansion of Medicaid might increase the uninsured rate among low-income households if higher minimum wages pushed them over eligibility thresholds. That is, among Medicaid-expansion states, states with higher minimum wages may have higher uninsured rates among lower income households than states with lower minimum wages.

To test for the potential heterogeneous effects, an indicator variable "Post 2014" that equals one for years 2014-2018 is created and interacted with the minimum wage variable. The Medicaid expansion variable is also interacted with the minimum wage. Table 3 shows the results. The coefficients on the interaction between the minimum wage and "Post 2014" are statistically significant and negative for all income groups, with point estimates declining in magnitude with income, while the coefficients on the minimum wage itself are not statistically significant. This indicates that the minimum wage led to a reduction in the uninsured rate after the ACA took effect in 2014. As expected, the coefficients on the interaction between the minimum wage and Medicaid expansion is statistically significant and positive for lower income households ( $<138 \%$ and 138-200\% FPL), while the coefficients on Medicaid expansion continue to be statistically significant and negative for these households. This suggests that the effect of Medicaid on the uninsured rate is partially offset by higher minimum wages, presumably because more minimum-wage workers become ineligible for Medicaid in Medicaid-expansion states. Overall, the results reveal heterogeneous effects by time (pre-ACA vs. post-ACA) and place (Medicaid-expansion states vs. non-expansion states).

For the lowest income group ( $<138 \%$ FPL), the magnitude suggests that a $\$ 1$ increase in the minimum wage is associated with a 1.0 percentage points decline (2.6-3.6) in the uninsured rate in Medicaid expansion states and a 3.6 percentage points decline for nonexpansion states. For the second lowest income group (138-200\% FLP), the effect of a $\$ 1$ increase in the minimum wage is a 1.7 percentage-point decline (1.8-3.5) in Medicaid expansion states and by a 3.5 percentage-point decline for non-expansion states. For groups 


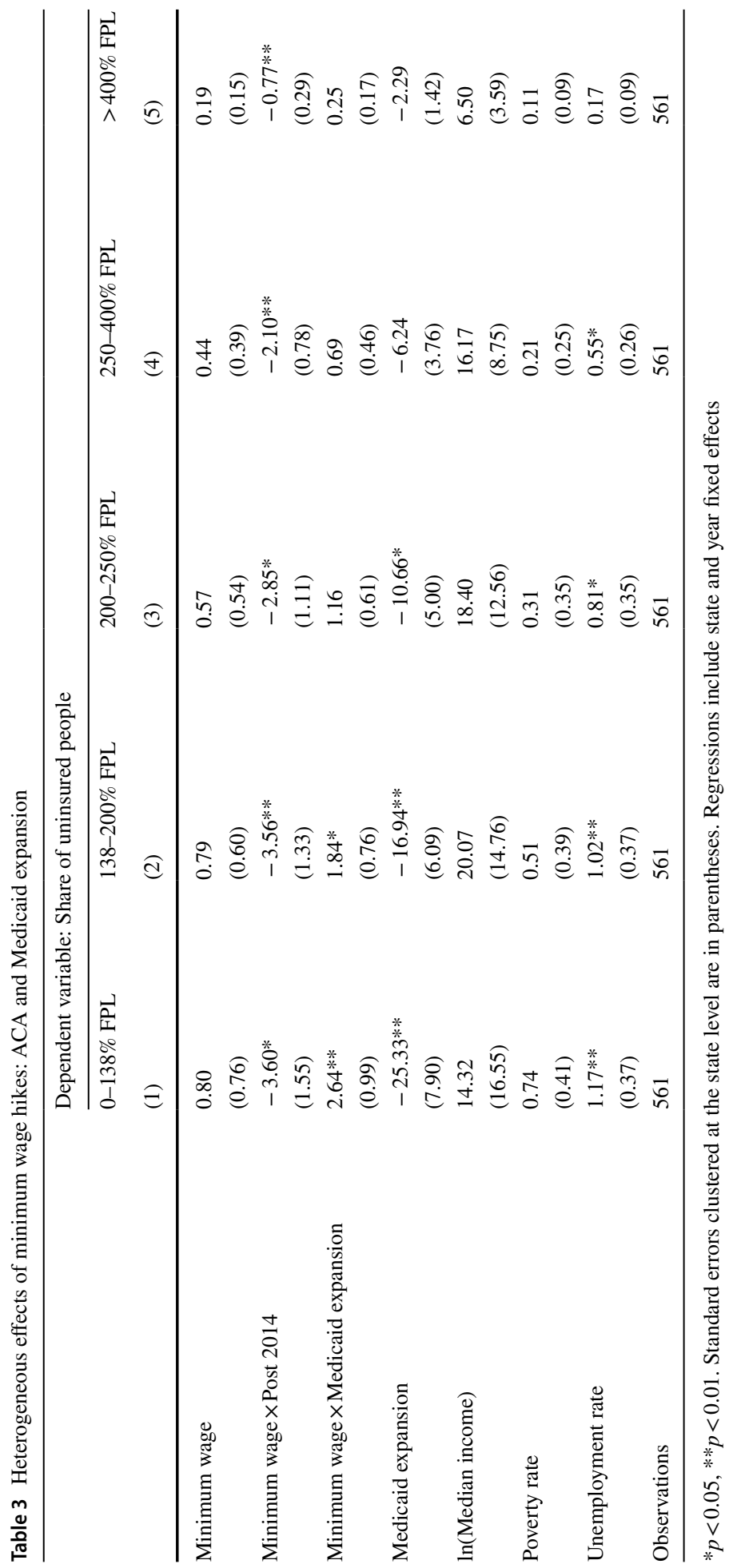


Table 4 Triple-difference regression results

Dependent variable: Share of uninsured people

(1)

(2)

Minimum wage $\times 0-138 \%$ FPL

$-0.23$

0.61

$(0.61)$

(0.75)

Minimum wage $\times 138-200 \%$ FPL

$-0.80$

0.60

(0.52)

(0.53)

Minimum wage $\times 200-250 \%$ FPL

$-0.87 *$

0.38

(0.41)

(0.45)

Minimum wage $\times 250-400 \%$ FPL

$-0.66^{*}$

0.25

(0.26)

(0.28)

Minimum wage $\times 0-138 \%$ FPL $\times$ Post 2014

$-2.84$

Minimum wage $\times 138-200 \%$ FPL $\times$ Post 2014

Minimum wage $\times 200-250 \%$ FPL $\times$ Post 2014

Minimum wage $\times 250-400 \%$ FPL $\times$ Post 2014

Minimum wage $\times 0-138 \%$ FPL $\times$ Medicaid expansion

Minimum wage $\times 138-200 \%$ FPL $\times$ Medicaid expansion

Minimum wage $\times 200-250 \%$ FPL $\times$ Medicaid expansion

Minimum wage $\times 250-400 \%$ FPL $\times$ Medicaid expansion

Observations

2805

2805

${ }^{*} p<0.05,{ }^{*} p<0.01$. Standard errors clustered at the state level are in parentheses. Regressions include state-by-year fixed effects, state-by-group fixed effects, and group-by-year fixed effects, as well as statelevel covariates interacted with income group dummies

with income above 200\% FPL, the magnitude of the estimated effect of a \$1 increase in the minimum wage on the uninsured rate is $2.8,2.1$, and 0.7 percentage points for higher income groups $200-250 \%, 250-400 \%$, and $>400 \%$, respectively, regardless of the state's Medicaid expansion status.

\section{Triple-difference}

While it is plausible that higher minimum wages helped households in the "200-250\% FPL" and "250-400\% FPL" categories obtain employer-sponsored coverage or purchase 
coverage through a marketplace, it is unlikely that the uninsured rate for households in the " $>400 \%$ FPL" income category is affected directly by higher minimum wages, as these households are least likely to have family members who earn the minimum wage. There are two possible explanations. First, the results reflect a sizeable role for spillover effects of minimum wage policy on higher wage workers. That is, the wage effects might be spilling over to people who earn above the minimum wage, as documented by Autor et al. (2016).

The second, perhaps more probable, explanation is that high minimum wage states experienced a decline in the uninsured rate due to the differential trends, which would violate the parallel trend assumption and thus raise a concern that the difference-in-differences estimate might be conflating the changes in the minimum wage with these trends. To account for the possibility that states were trending differently over this period, a tripledifference regression is estimated, using income group "> $400 \%$ FPL", whose exposure to minimum wage increases is minimal, as the reference group. As long as these trends are similar for all income groups, the triple-difference controls for the effect of the differential trends.

Column (1) in Table 4 reports coefficients on interactions between the minimum wage and indicators for income groups. Recall that the reported coefficients give the differential impact of minimum wage increases on the uninsured rate for each income group, relative to high-income group " $>400 \%$ FPL". The coefficients on the minimum wage interacted with income groups "250-400\% FPL" and "200-250\% FPL" remain statistically significant. The magnitude indicates that a $\$ 1$ minimum wage increase is associated with a $0.6-0.8$ percentage point decline in the uninsured rate for these income groups, which is roughly what one would expect by simply comparing coefficients across income groups from Table 2 and differencing out the coefficient for " $>400 \%$ FLP". While it is unlikely that minimum wage workers are the breadwinners among income groups "200-250\% FPL" and "250-400\% FPL", it is plausible that many minimum wage workers are secondary earners in these households, Since households in these income groups are not eligible for Medicaid, they might have obtained private health insurance, either through employer-sponsored insurance or an insurance marketplace, after a minimum wage hike.

Finally, column (2) in Table 4 reports the triple-difference estimates further interacted with the "Post 2014" dummy and the Medicaid expansion variable. Again, the magnitude of the coefficients on the interactions are roughly what one would expect by comparing coefficients across income groups from Table 3 and differencing out the coefficient for "> $400 \%$ FLP". The overall conclusion is similar to that from the difference-in-differences regressions in Table 3. The estimated effects suggest that minimum wage hikes seem to have led to a reduction in the uninsured rate after 2014 (though the coefficient is only statistically significant at the ten percent level for the lowest income group), but Medicaid expansions seem to mitigate the effect of the minimum wage among lower income households. 


\section{Conclusions}

This study has examined the link between state-level minimum wage increases and uninsured rates. The event study models support parallel pre-trends, suggesting that states that increased their minimum wages did not experience differential trends in uninsured rates in the years leading up to the minimum wage hike. The baseline difference-in-differences estimates provide suggestive evidence that the minimum wage tends to reduce the uninsured rate, but further analysis reveals that the effect of the minimum wage was concentrated after the ACA took effect in 2014. For the period before the ACA (2008-2013), the precision of the estimates is too low to conclude that the minimum wage had any effect on the uninsured rate. The triple-difference models yield similar conclusions. Overall, evidence suggests that higher minimum wages may encourage people to obtain health insurance through their employers or the ACA marketplace. The ACA's individual mandate provision might have played a role in the effect of the minimum wage on the uninsured rate as well.

This study also finds indications of heterogeneous effects by Medicaid expansion status. The effect of the minimum wage on the uninsured rate is smaller among Medicaidexpansion states, presumably because some minimum-wage workers lose their Medicaid eligibility in states where childless adults are eligible. Unfortunately, it is impossible to answer definitively whether the ACA provisions and Medicaid expansions played some role in how the minimum wage affects the uninsured rate, because the SAHIE does not contain information on the type of insurance (employer-sponsored, purchased through the ACA marketplace, or public).

Nevertheless, at the minimum, the findings suggest that higher minimum wages do not lead to higher uninsured rates. For policymakers who wish to raise the minimum wage but worry that more people might become uninsured, either because employers choose to stop offering employer-sponsored health insurance or many minimum wage workers losing eligibility for Medicaid, the finding in this paper might provide some guidance.

One limitation of this study is that it is not clear how many people shifted from Medicaid to insurance purchased through the state's health care exchanges. Consequently, this study cannot say whether the minimum wage would result in state-related Medicaid savings by reducing a state's contribution toward the costs of health care coverage for its residents. Also, it is not clear whether workers who shifted from Medicaid to private health insurance were financially better off overall, as they might end up paying more for coverage through employer-sponsored insurance or through an insurance marketplace. Future research should address these issues.

\section{Appendix}

See Tables 5, 6, and 7. 


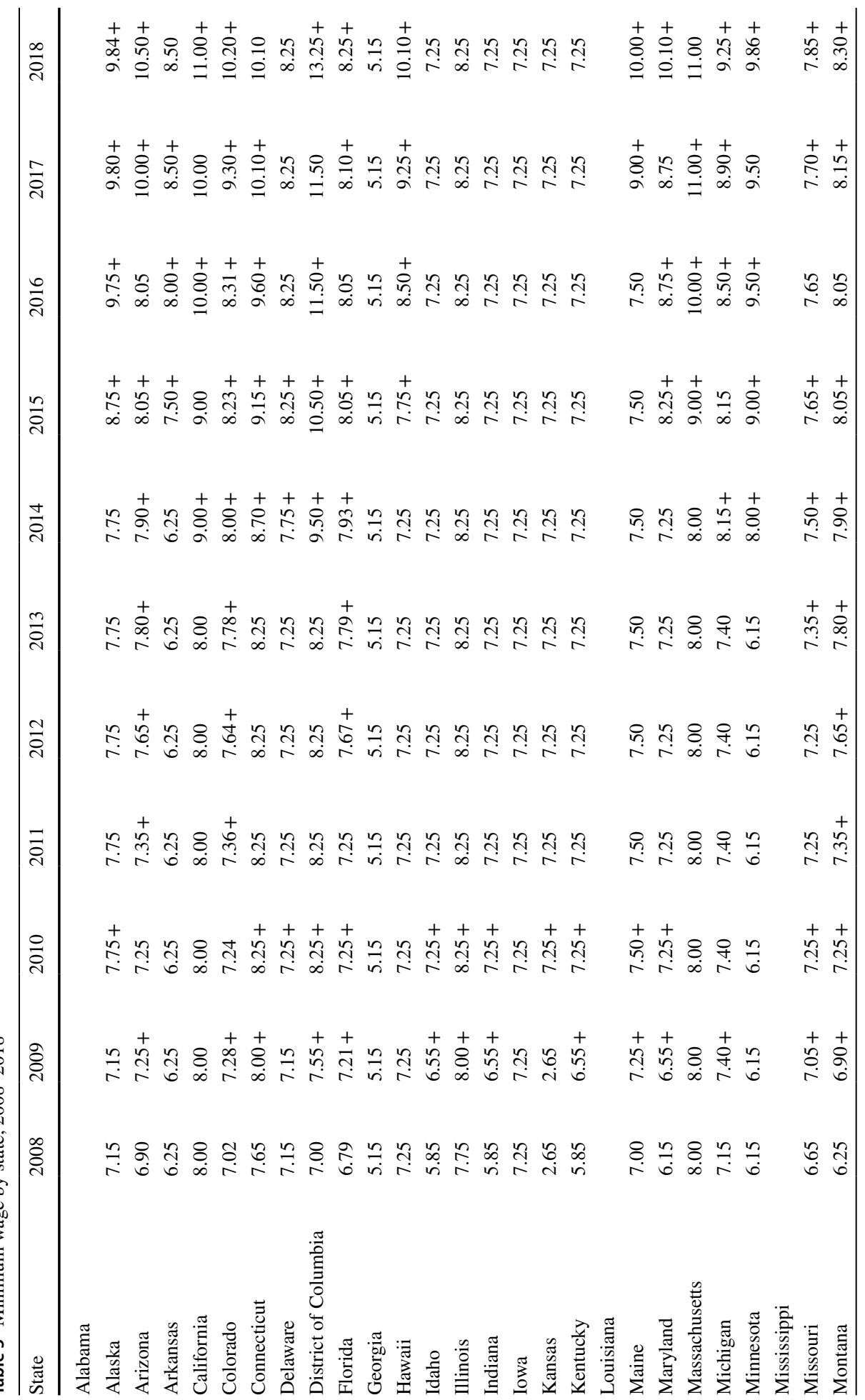




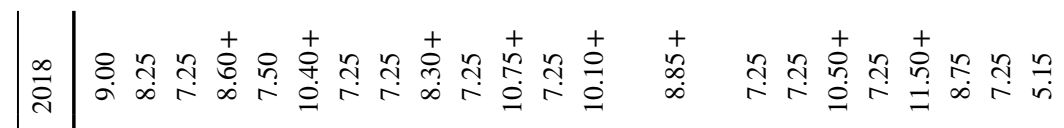

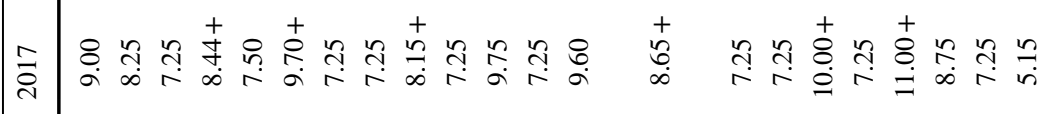

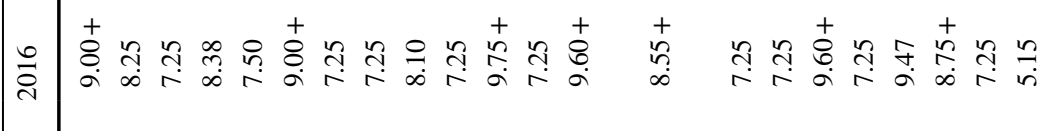

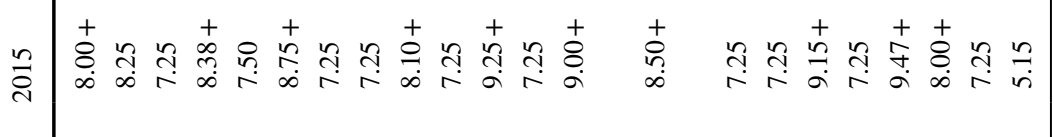

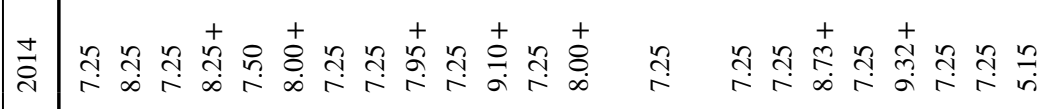

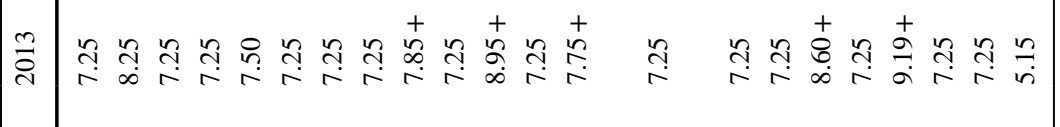

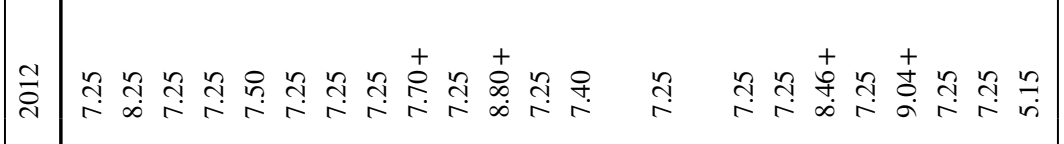

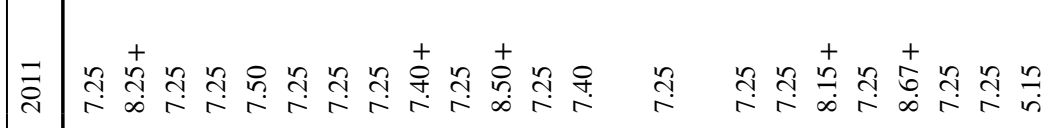

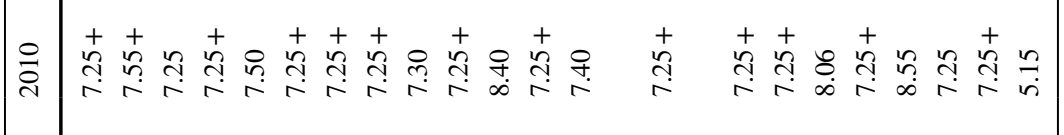

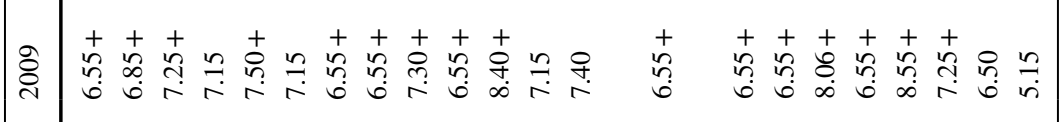

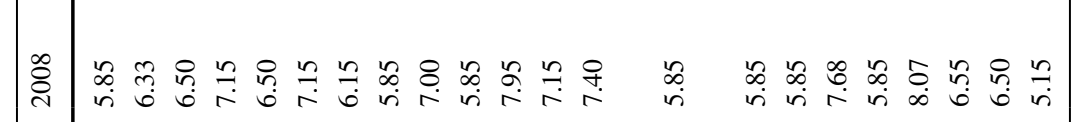

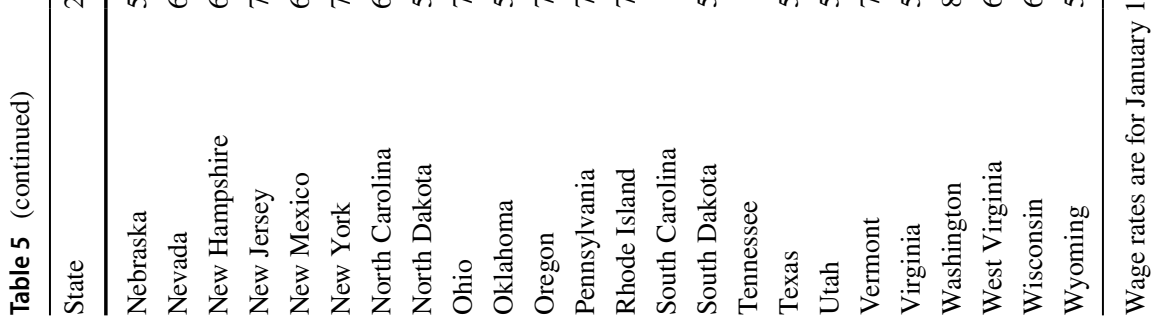


Table 6 Summary statistics by group: 2008-2018

\begin{tabular}{lll}
\hline Variable & $\begin{array}{l}\text { Minimum wage } \\
\text { states }\end{array}$ & $\begin{array}{l}\text { Non-mini- } \\
\text { mum wage } \\
\text { states }\end{array}$ \\
\hline$\%$ uninsured (0-138\% FPL) & 28.38 & 36.39 \\
$\%$ uninsured (138-200\% FPL) & 25.62 & 30.12 \\
$\%$ uninsured (200-250\% FPL) & 20.38 & 23.21 \\
$\%$ uninsured (250-400\% FPL) & 13.22 & 14.92 \\
$\%$ uninsured (>400\% FPL) & 5.11 & 6.10 \\
Medicaid expansion & 0.41 & 0.09 \\
Unemployment & 6.3 & 6.0 \\
Median income & 56,562 & 50,042 \\
Poverty & 13.1 & 15.0 \\
Number of states & 35 & 16 \\
\hline
\end{tabular}

Table 7 Event study variables: Oregon and Texas

\begin{tabular}{|c|c|c|c|c|c|c|c|c|c|c|c|c|}
\hline Year & State & Minimum Wage & Change & -4 & -3 & -2 & -1 & 0 & +1 & +2 & +3 & +4 \\
\hline 2005 & Oregon & 7.25 & 0.20 & & & & & & & & & \\
\hline 2006 & Oregon & 7.50 & 0.25 & & & & & & & & & \\
\hline 2007 & Oregon & 7.80 & 0.30 & & & & & & & & & \\
\hline 2008 & Oregon & 7.95 & 0.15 & 3.50 & 0.10 & 0.00 & 0.45 & 0.15 & 0.30 & 0.25 & 0.20 & 0.00 \\
\hline 2009 & Oregon & 8.40 & 0.45 & 3.20 & 0.30 & 0.10 & 0.00 & 0.45 & 0.15 & 0.30 & 0.25 & 0.20 \\
\hline 2010 & Oregon & 8.40 & 0.00 & 3.05 & 0.15 & 0.30 & 0.10 & 0.00 & 0.45 & 0.15 & 0.30 & 0.45 \\
\hline 2011 & Oregon & 8.50 & 0.10 & 2.90 & 0.15 & 0.15 & 0.30 & 0.10 & 0.00 & 0.45 & 0.15 & 0.75 \\
\hline 2012 & Oregon & 8.80 & 0.30 & 2.75 & 0.15 & 0.15 & 0.15 & 0.30 & 0.10 & 0.00 & 0.45 & 0.90 \\
\hline 2013 & Oregon & 8.95 & 0.15 & 2.25 & 0.50 & 0.15 & 0.15 & 0.15 & 0.30 & 0.10 & 0.00 & 1.35 \\
\hline 2014 & Oregon & 9.10 & 0.15 & 2.25 & 0.00 & 0.50 & 0.15 & 0.15 & 0.15 & 0.30 & 0.10 & 1.35 \\
\hline 2015 & Oregon & 9.25 & 0.15 & 1.25 & 1.00 & 0.00 & 0.50 & 0.15 & 0.15 & 0.15 & 0.30 & 1.45 \\
\hline 2016 & Oregon & 9.75 & 0.50 & 0.75 & 0.50 & 1.00 & 0.00 & 0.50 & 0.15 & 0.15 & 0.15 & 1.75 \\
\hline 2017 & Oregon & 9.75 & 0.00 & 0.00 & 0.75 & 0.50 & 1.00 & 0.00 & 0.50 & 0.15 & 0.15 & 1.90 \\
\hline 2018 & Oregon & 10.75 & 1.00 & 0.00 & 0.00 & 0.75 & 0.50 & 1.00 & 0.00 & 0.50 & 0.15 & 2.05 \\
\hline 2019 & Oregon & 11.25 & 0.50 & & & & & & & & & \\
\hline 2020 & Oregon & 12.00 & 0.75 & & & & & & & & & \\
\hline 2021 & Oregon & 12.00 & 0.00 & & & & & & & & & \\
\hline 2005 & Texas & 5.15 & 0.00 & & & & & & & & & \\
\hline 2006 & Texas & 5.15 & 0.00 & & & & & & & & & \\
\hline 2007 & Texas & 5.15 & 0.00 & & & & & & & & & \\
\hline 2008 & Texas & 5.85 & 0.70 & 0.00 & 0.00 & 0.70 & 0.70 & 0.70 & 0.00 & 0.00 & 0.00 & 0.00 \\
\hline 2009 & Texas & 6.55 & 0.70 & 0.00 & 0.00 & 0.00 & 0.70 & 0.70 & 0.70 & 0.00 & 0.00 & 0.00 \\
\hline 2010 & Texas & 7.25 & 0.70 & 0.00 & 0.00 & 0.00 & 0.00 & 0.70 & 0.70 & 0.70 & 0.00 & 0.00 \\
\hline 2011 & Texas & 7.25 & 0.00 & 0.00 & 0.00 & 0.00 & 0.00 & 0.00 & 0.70 & 0.70 & 0.70 & 0.00 \\
\hline 2012 & Texas & 7.25 & 0.00 & 0.00 & 0.00 & 0.00 & 0.00 & 0.00 & 0.00 & 0.70 & 0.70 & 0.70 \\
\hline 2013 & Texas & 7.25 & 0.00 & 0.00 & 0.00 & 0.00 & 0.00 & 0.00 & 0.00 & 0.00 & 0.70 & 1.40 \\
\hline 2014 & Texas & 7.25 & 0.00 & 0.00 & 0.00 & 0.00 & 0.00 & 0.00 & 0.00 & 0.00 & 0.00 & 2.10 \\
\hline 2015 & Texas & 7.25 & 0.00 & 0.00 & 0.00 & 0.00 & 0.00 & 0.00 & 0.00 & 0.00 & 0.00 & 2.10 \\
\hline
\end{tabular}


Table 7 (continued)

\begin{tabular}{|c|c|c|c|c|c|c|c|c|c|c|c|c|}
\hline Year & State & Minimum Wage & Change & -4 & -3 & -2 & -1 & 0 & +1 & +2 & +3 & +4 \\
\hline 2016 & Texas & 7.25 & 0.00 & 0.00 & 0.00 & 0.00 & 0.00 & 0.00 & 0.00 & 0.00 & 0.00 & 2.10 \\
\hline 2017 & Texas & 7.25 & 0.00 & 0.00 & 0.00 & 0.00 & 0.00 & 0.00 & 0.00 & 0.00 & 0.00 & 2.10 \\
\hline 2018 & Texas & 7.25 & 0.00 & 0.00 & 0.00 & 0.00 & 0.00 & 0.00 & 0.00 & 0.00 & 0.00 & 2.10 \\
\hline 2019 & Texas & 7.25 & 0.00 & & & & & & & & & \\
\hline 2020 & Texas & 7.25 & 0.00 & & & & & & & & & \\
\hline 2021 & Texas & 7.25 & 0.00 & & & & & & & & & \\
\hline
\end{tabular}

\section{References}

Allegretto, S. A., ArindrajitDube, A., Reich, M., \& Zipperer, B. (2017). Credible research designs for minimum wage studies: A response to Neumark, Salas and Wascher. ILR Review, 70(3), 559-592.

Autor, D. H., Manning, A., \& Smith, C. L. (2016). The contribution of the minimum wage to US wage inequality over three decades: A reassessment. American Economic Journal: Applied Economics, 8(1), 58-99.

Bindman, A. B. (2015). A healthy living wage. Journal of the American Medical Association Forum, 314 , 2224-2225.

Cauchi, R. (2016). ACA requirements for medium and large employers to offer health coverage. In The national conference of state legislatures. https://www.ncsl.org/documents/health/aca_requirements_ for_employers.pdf

Clemens, J., Kahn L. B., \& Meer, J. (2018). The minimum wage, fringe benefits, and worker welfare. In NBER working paper.

Falk, A., Fehr, E., \& Zehnder, C. (2006). Fairness perceptions and reservation wages-The behavioral effects of minimum wage laws. The Quarterly Journal of Economics, 121(4), 1347-1381.

Federal Reserve Bank of St. Louis. (2021). Consumer price index for all urban consumers: All items in U.S. city average. https://fred.stlouisfed.org/series/CPIAUCSL

Kaiser Family Foundation. (2021). Status of state Medicaid expansion decisions. http://kff.org/healthreform/state-indicator/state-activity-around-expanding-medicaid-under-the-affordable-care-act

Leigh, J. P., Du Leigh, W. A., \& J. . (2019). Minimum wages and public health: A literature review. Preventive Medicine, 118, 122-134.

Schmidheiny, K., \& Siegloch, S. (2019). On event study designs and distributed-lag models: Equivalence, generalization and practical implications. IZA DP No. 12079.

Simon, K. L., \& Kaestner, R. (2004). Do minimum wages affect non-wage job attributes? Evidence on fringe benefits. Industrial and Labor Relations Review, 58(1), 52-70.

U.S. Bureau of Labor Statistics. (2020). Local area unemployment statistics, statewide data, annual average series. https://www.bls.gov/lau/rdscnp16.htm

U.S. Census Bureau. (2020a). Small area income and poverty estimates. https://www.census.gov/programssurveys/saipe/data/datasets.html

U.S. Census Bureau. (2020b). Annual state resident population estimates for 5 race groups by age, sex, and hispanic origin: April 1, 2010 to July 1, 2018. https:/www.census.gov/data/tables/time-series/demo/ popest/2010s-state-detail.html

U.S. Census Bureau. (2021). 2008-2018 small area health insurance estimates (SAHIE). https://www.census.gov/data/datasets/time-series/demo/sahie/estimates-acs.html

U.S. Department of Labor. (2020). Changes in basic minimum wages in non-farm employment under state law: Selected years 1968 to 2020. https://www.dol.gov/agencies/whd/state/minimum-wage/history

Publisher's Note Springer Nature remains neutral with regard to jurisdictional claims in published maps and institutional affiliations. 